\title{
ПРОГНОЗИРОВАНИЕ НОЧНОЙ ГИПОГЛИКЕМИИ У ПАЦИЕНТОВ С САХАРНЫМ ДИАБЕТОМ 1 ТИПА: ВОЗМОЖНОСТИ МАШИННОГО ОБУЧЕНИЯ
}

\author{
1,2Бериков В.Б., 1,2Неделько В.М., 'Семенова Ю.Ф., 'Климонтов В.В.
}

' Научно-исследовательский институт клинической и экспериментальной лимфологии - филиал ФИЦ Институт цитологии и генетики СО РАН, Новосибирск

${ }^{2}$ Институт математики им. С.Л. Соболева СО РАН, Новосибирск

ЦЕЛЬ: разработать технологию прогнозирования ночной гипогликемии (НГ) у госпитализированных пациентов с сахарным диабетом 1 типа (СД1) на основе данных непрерывного мониторинга глюкозы (НМГ) и методов машинного обучения.

МАТЕРИАЛЫ И МЕТОДЫ: ИспользОван набор записей НМГ, полУченных от 406 взрослых пациентов с СД1, проходивших лечение в эндокринологическом отделении клиники. Эпизод НГ был определен как снижение уровня глюкозы<3,9 ммоль/л в течение не менее 15 минут в интервале от 0 до 6 часов утра. Был сформирован набор характеристик, полученных путем математической обработки кривых НМГ, таких, как средний уровень глюкозы, ее минимальное и максимальное значения, соотношение времени роста и времени спада, автокорреляции с разным лагом, и ряд параметров вариабельности уровня глюкозы. Эти характеристики были использованы в качестве потенциальных предикторов НГ. Полученная выборка являлась несбалансированной, поэтому для анализа были использованы методы «undersampling» и «oversampling». Для прогнозирования НГ и оценки информативности предикторов использовался метод случайного леса решений RF (Random Forest). Качество предсказания оценивалось по тестовой выборке с использованием кросс-валидации на основе метода Монте-Карло.

Работа выполнена за счет гранта Российского научного фонда (проект 20-15-00057).

PЕЗУЛЬТАТЫ: в зависимости от длины предикторной последовательности (30 мин-1 час) и горизонта прогнозирования (5-30 мин) было проанализировано 209-256 записей НМГ как минимум с одним эпизодом НГ и около $4 \cdot 10^{4}$ записей без НГ. Использование процедур сэмплинга улучшило качество прогноза, что привело к увеличению чувствительности и специфичности на 3-7\%. Достигнутая чувствительность и специфичность варьировала от 98\% и 97\% соответственно для горизонта 5 минут до 85\% и 87\% для горизонта 30 минут. Средний и минимальный уровни глюкозы, коэффициент линейного тренда и 5-минутный нисходящий градиент были наиболее важными предикторами, оцененными с помощью метода RF. Установлено, что у пациентов с гипогликемией предшествующее снижение уровня глюкозы происходило более медленными темпами и в течение более длительного времени.

Выводы: результаты демонстрируют, что машинное обучение, основанное на данных НМГ, является перспективным подходом для прогнозирования эпизодов НГ у пациентов с СД1.

КЛЮЧЕВЫЕ СЛОВА: сахарный диабет; непрерывный мониторинг глюкозы; гипогликемия; машинное обучение. 